\title{
Klinische epidemiologie: maximale detrusorcontractie- kracht gerelateerd aan leeftijd en geslacht
}

\author{
Peter F. W. M. Rosier · Celine S. ten Donkelaar · Laetitia M. O. de Kort
}

Published online: 8 January 2020

(C) The Author(s) 2019

Samenvatting In deze cross-sectionele epidemiologische studie is nagegaan wat de relatie is tussen maximale detrusorcontractiekracht en leeftijd bij patiënten die waren verwezen met lower urinary tract symptoms (LUTS). Hiertoe is een retrospectieve analyse uitgevoerd op de resultaten van urodynamisch onderzoek dat werd uitgevoerd bij 1.308 patiënten. De detrusorcontractiekracht gedurende mictie werd vergeleken tussen mannen en vrouwen en tussen verschillende leeftijdsgroepen (range 20-90 jaar). Het betreffen cross-sectionele data van patiënten met LUTS die waren verwezen naar een specialistisch centrum. In hogere leeftijdsgroepen werd er een lagere maximale detrusorcontractie waargenomen. De maximale detrusorcontractiekracht was gemiddeld $30 \%$ minder krachtig bij oudere vrouwen en $12 \%$ minder krachtig bij oudere mannen dan bij jongere vrouwen en mannen. Uit dit onderzoek blijkt dat zowel bij vrouwen als bij mannen met LUTS de maximale detrusorcontractiekracht van de oudere patiënt lager is dan die van de jongere patiënt. Het verschil in maximale detrusorcontractiekracht in relatie tot de leeftijd is groter bij vrouwen dan bij mannen. Deze bevindingen kunnen niet zonder meer gegeneraliseerd worden naar een asymptomatische populatie.

\footnotetext{
Dit artikel is een vertaling van Rosier PFWM, ten Donkelaar CS, de Kort LM: Clinical epidemiology: detrusor voiding contraction maximum power, related to ageing, dat werd gepubliceerd in Urology 2019;124:72-7. PMID: 30447267.

P. F. W. M. Rosier, PhD · C. S. ten Donkelaar .

prof. dr. L. M. O. de Kort $(\bowtie)$

afdeling Urologie, Universitair Medisch Centrum, Utrecht,

Nederland

l.m.o.dekort@umcutrecht.nl
}

Trefwoorden uroflowmetrie · veroudering · epidemiologie

\section{Clinical epidemiology: detrusor voiding contraction maximum power related to ageing and gender}

\begin{abstract}
To report clinical epidemiology of detrusor (bladder) muscle contraction maximum related to ageing in patients referred with signs and symptoms of lower urinary tract dysfunction. One thousand three hundred and eight urodynamic pressure-flow measurements were analyzed in retrospective. Standard measures of detrusor muscle voiding contraction strength were compared for gender and ranked by age (range 20-90 years). A decline in maximum detrusor contraction strength was observed when the results were ranked according to age. Detrusor muscle maximum voiding contraction was on average $30 \%$ less powerful in older women and $12 \%$ less powerful in the aged men, when compared to the younger. This is transversal data - interpreted in a longitudinal manner - and from persons referred to specialist care with (the full spectrum of) signs and symptoms of lower urinary tract dysfunction. Clinical epidemiologic evaluation of patients referred with lower urinary tract symptoms, found lower detrusor maximum contraction strength in higher-age cohorts, both for women as for men. The maximum detrusor strength difference in association with age was larger in women than in men. These findings cannot simply be generalized to an asymptomatic population.
\end{abstract}

Keywords urodynamics · aging · epidemiology 


\section{Introductie}

Ouder worden is geassocieerd met verlies van dwarsgestreept spierweefsel en een algemene afname van spiercontractiliteit [1]. Veroudering heeft mogelijk ook effect op de - niet dwarsgestreepte - musculus detrusor [2]. Een expertreview suggereert dat detrusor-onderactiviteit (DO) mogelijk een van de oorzaken is van de groeiende prevalentie van lower urinary tract symptoms (LUTS) bij ouderen [3]. De huidige definitie van onderactiviteit van de International Continence Society (ICS) beperkt zich tot een kwalitatieve beschrijving: '[...] een contractie met verminderde kracht en/of duur resulterend in verlengde blaaslediging en het falen van volledige blaaslediging binnen een normale tijd' [4]. In recentelijk uitgevoerd onderzoek werd gesuggereerd dat er een relatie bestaat tussen de symptomen van LUTS en het klinisch spectrum van het onderactief blaassyndroom [5]. Hoewel de kracht van de musculus detrusor binnen de verschillende leeftijdsgroepen zal variëren, zal de detrusorcontractiekracht binnen een voldoende grote populatie normaal verdeeld zijn. Momenteel is weinig bekend over de leeftijdsgerelateerde klinischrelevante afkapwaarden (zwak/sterk) van de detrusorcontractiekracht van, met name, vrouwen. Hiervoor is klinisch-epidemiologisch onderzoek nodig.

Om detrusorcontractie en urineflow gedurende de mictie objectief te kunnen analyseren, is urodynamische pressure flowmetrie (P-Q) nodig. Er zijn drie methoden om de detrusorcontractiekracht te bepalen. Bij de eerste methode wordt de bladder contractility index (BCI) berekend, een index die is gebaseerd op detrusordruk tijdens maximale flow $\left(\mathrm{p}_{\operatorname{det}} \mathrm{Q}_{\max }\right)$ en maximale flow $\left(\mathrm{Q}_{\max }\right)$. De detrusorcontractiekracht kan ook worden bepaald met het linearized passive urethral resistance relation (LinPURR) nomogram, ofwel het Schaefer-nomogram, dat is gebaseerd op $\mathrm{p}_{\text {det }} \mathrm{Q}_{\max }$ en $\mathrm{Q}_{\max }$. Deze contractiliteitsgroepen kunnen verder verdeeld worden over een continue schaal met de geprojecteerde isovolumetrische detrusordruk (projected isovolumetric detrusor pressure; PIP) of de detrusorcoëfficiënt [6], vergelijkbaar met de BCI. Een derde methode om de detrusorcontractiekracht gedurende mictie mee te kwantificeren, is de Watts factor $\left(\mathrm{W} ; \mathrm{W} / \mathrm{m}^{2}\right)$. De meeste studies geven alleen de maximale $\mathrm{W}$-waarde aan, de $\mathrm{W}_{\text {max }}$.

Zowel de $\mathrm{W}_{\max }$ als de BCI resulteren in parameters op een continue schaal, die goed bruikbaar zijn voor klinische epidemiologie. De LinPURR en de BCI correleren statistisch met de $W_{\max }$ [8], maar de $W_{\max }$ wordt voor onderzoeksdoeleinden nauwkeuriger geacht [9]. Zowel de LinPURR als de BCI zijn niet specifiek gevalideerd voor vrouwen, hoewel de hydrodynamische (urodynamische) principes voor de mictie van mannen en vrouwen vergelijkbaar zijn [10].

De metingen in deze studie geven de mogelijkheid om (de geschatte maximale) detrusorkracht in een continuüm weer te geven, waarbij DO gediagnosti- ceerd kan worden als de waarde onder een bepaalde afkapwaarde komt. Deze studie heeft echter niet de intentie om de (klinische) prevalentie van DO weer te geven.

DO kan verschillende oorzaken hebben, zoals neurogene DO bij caudale of sacrale plexuslaesies of andere relevante neurologische afwijkingen. Myogene DO kan ontstaan na acute of chronische overrekking/urineretentie, polyneuropathie of microangiopathieën, al dan niet op basis van diabetes mellitus [11]. Bovendien kan DO veroorzaakt worden door verminderende functie vanwege veroudering, zonder de hiervoor genoemde specifieke comorbiditeiten. Hoewel sarcopenie (vermindering van dwarsgestreept spierweefsel) uitvoeriger en meer specifiek onderzocht is dan veroudering van glad spierweefsel [12], zou de pathofysiologie op cellulair niveau mogelijk vergelijkbaar zijn, zoals reeds geobserveerd is bij gastro-intestinaal en vasculair glad spierweefsel [13, 14]. Dat subjectieve symptomen verschillen in verschillende stadia en gradering van ziekte of disfunctie is in de geneeskunde niet ongewoon en zal op eenzelfde manier optreden bij DO en het onderactief blaassyndroom. De klinische relatie tussen verschillende soorten LUTS en ouder worden zijn methodologisch goed onderzocht en recent beschreven [15], maar de klinische epidemiologie van DO op grote schaal en specifiek in relatie tot leeftijd is nooit goed geëvalueerd. Eén studie beschrijft de prevalentie van DO bij mannen en vrouwen van verschillende leeftijden. Deze studie is echter uitgevoerd met, met name voor de vrouwen, niet-gestandaardiseerde parameters en leverde enkel dichotome resultaten op [16]. Een andere studie onderzocht afwijkingen in blaascapaciteit in drie verschillende leeftijdscohorten (20-39, 40-59 en >60 jaar, die 30 jaar besloeg), met in elk cohort ongeveer 30 vrouwen, en beschreef dat de PIP lager was in het laatste cohort [17]. In deze studie wordt de BCI niet weergegeven, maar bij eigen berekening uit de weergegeven data, zijn de waarden daarvan normaal.

Wij beschrijven de klinische epidemiologie van de maximale detrusorcontractiekracht $\left(\mathrm{W}_{\max }\right)$, op een continue schaal, in relatie tot leeftijd en geslacht. De uitkomsten zijn gebaseerd op een grote serie nauwkeurige pressure-flowcontractiemetingen verkregen uit klinisch routinematig, ICS-gestandaardiseerde, urodynamische pressure-flowstudies.

\section{Studie opzet, materiaal en methoden}

Er werden 1.308 opeenvolgende uitkomsten van pressure-flowstudies geanalyseerd van porties > $100 \mathrm{ml}$. Alle geïncludeerde patiënten waren ouder dan 18 jaar. In alle gevallen werd het urodynamisch onderzoek verricht vanwege hinderlijke LUTS. Alleen de voor de eerste maal verrichtte urodynamische onderzoeken werden geïncludeerd. Patiënten met neurologische afwijkingen, diabetes mellitus, patiënten die eerder 
Tabel 1 Pressure flow onderzoek parameters $t$ testen (gecorrigeerd voor variantie): mannen vs vrouwen en correlatie met leeftijd; mannen en vrouwen

\begin{tabular}{|c|c|c|c|c|c|c|c|}
\hline \multicolumn{2}{|c|}{ pressure flow parameters } & $Q_{\max }$ & $P_{\text {detgmax }}$ & URA & BOOI & $B C l$ & $W_{\max }$ \\
\hline \multirow[t]{3}{*}{ vrouwen } & $N$ & 375 & 375 & 360 & 375 & 375 & 375 \\
\hline & mean & 19,2 & 27,6 & 12,7 & $-10,9$ & 123,7 & 11,9 \\
\hline & s.d. & 10,3 & 27,4 & 8,3 & 36,2 & 55,4 & 8,6 \\
\hline \multirow[t]{3}{*}{ mannen } & $N$ & 800 & 798 & 795 & 797 & 797 & 793 \\
\hline & mean & 11,2 & 59,5 & 29,8 & 37,2 & 114,9 & 13,6 \\
\hline & s.d. & 6,0 & 27,6 & 16,2 & 33,3 & 33,6 & 8,6 \\
\hline t test & vrouwen/mannen & $<0,001$ & $<0,001$ & $<0,001$ & $<0,001$ & 0,001 & 0,003 \\
\hline \multirow[t]{2}{*}{ ALL } & mean & 13,7 & 49,3 & 24,5 & 21,8 & 117,7 & 13,0 \\
\hline & s.d. & 8,5 & 31,3 & 16,3 & 40,9 & 41,9 & 8,6 \\
\hline \multicolumn{2}{|c|}{ correlatie pressure flow vs leeftijd } & $Q_{\max }$ & $P_{\text {detgmax }}$ & URA & BOOI & $\mathrm{BCl}$ & $W_{\max }$ \\
\hline \multirow[t]{2}{*}{ leeftijd vrouwen } & Pearson & $-0,231^{\star \star}$ & $-0,230^{\star \star}$ & $-0,023$ & $-0,005$ & $-0,343^{\star \star}$ & $-0,305^{\star \star}$ \\
\hline & sig. $P$ & $<0,001$ & $<0,001$ & 0,661 & 0,926 & $<0,001$ & $<0,001$ \\
\hline \multirow[t]{2}{*}{ leeftijd mannen } & Pearson & $-0,286^{\star \star}$ & $0,081^{*}$ & $0,205^{\star *}$ & $0,162^{* *}$ & $-0,132^{\star \star}$ & $-0,191^{\text {* }}$ \\
\hline & sig. $P$ & $<0,001$ & 0,023 & $<0,001$ & $<0,001$ & $<0,001$ & $<0,001$ \\
\hline \multirow[t]{2}{*}{ leeftijd allen } & Pearson & $-0,327^{\star \star}$ & $0,069^{*}$ & $0,234^{\star \star}$ & $0,216^{\star \star}$ & $-0,183^{\star \star}$ & $-0,243^{\star \star}$ \\
\hline & sig. $P$ & $<0,001$ & 0,012 & $<0,001$ & $<0,001$ & $<0,001$ & $<0,001$ \\
\hline
\end{tabular}

relevante chirurgische ingrepen ondergingen, patiënten met congenitale afwijkingen die effect hebben op LUTS en patiënten die tijdens het onderzoek een urineweginfectie hadden, werden geëxcludeerd.

P-Q-metingen werden volgens huidige ICS-standaard uitgevoerd, met behulp van een met vloeistof gevulde uitwendige druksensor, $30-40 \mathrm{ml} / \mathrm{min}$ vullingscystometrie met fysiologisch zout, in privacy, zittend voor vrouwen ( $n=374)$ en mannen $(n=795)$ in voorkeurshouding $(75 \%$ staand), met een $7 \mathrm{~F}$-dubbellumen transurethrale katheter [18, 19].

Omdat de setting tijdens het urodynamisch onderzoek door mentale stress (sympathische activiteit) een niet-representatieve mictie kon veroorzaken (door inhibitie van detrusorcontractie en/of verminderde relaxatie van de uitgangsweerstand), werden alleen voor de patiënt representatieve micties geïncludeerd. Hoge postmictieresiduen werden niet geëxcludeerd.

Na handmatige correctie van (piek)artefacten van $\mathrm{Q}_{\max }$ werden de $\mathrm{p}_{\operatorname{det}} \mathrm{Q}_{\max }$, de blaasuitgangobstructieindex (BOOI), de BCI en de blaasuitgangsweerstand (URA) berekend. $\mathrm{W}_{\max }$-uitschieters traden vooral op net voor het einde van de mictie; deze werden echter niet geëxcludeerd voor deze analyse. Associatie met leeftijd werd geanalyseerd met de ANOVA-test en daarnaast per geslacht weergegeven in een scatterplot met toevoeging van een regressiecoëfficiënt.

\section{Resultaten}

In tab. 1 staan per geslacht de gemiddelde uitkomsten van de pressure-flowstudies en de resultaten van de $t$-test, gecorrigeerd voor variantie en de (Pearson) correlatie van deze parameters met leeftijd. Verschillen tussen geslachten zijn statistisch significant, hoe- wel de grootste absolute verschillen in het gemiddelde gezien worden bij aan flow gerelateerde parameters, zoals de $\mathrm{Q}_{\max }$, de URA en de BOOI. Mannen hebben een hogere $p_{\text {det }} Q_{\max }$ en een lagere $Q_{\max }$ in vergelijking met vrouwen. De URA en de BOOI zijn bij de vrouwen niet gecorreleerd met leeftijd, terwijl dat bij de mannen wel zo is. Bij de vrouwen is de $\mathrm{p}_{\text {det }} \mathrm{Q}_{\max }$ gecorreleerd met de leeftijd.

De scatterplot in fig. la laat zien dat zowel oudere mannen als oudere vrouwen een lagere $\mathrm{W}_{\max }$ hebben (Y-as). Bij mannen is de met de leeftijd geassocieerde afname (X-as), minder dan bij vrouwen, zoals gedemonstreerd wordt met de lineaire (regressie) $R^{2}$. Van de weergegeven leeftijdsgroep (18-96 jaar) is de $\mathrm{R}^{2} \mathrm{bij}$ de mannen 0,018 en bij de vrouwen 0,118. In tab. 2 staan de gemiddelde waarden van $\mathrm{W}_{\max }$ per leeftijdsdecade met ANOVA voor leeftijdsgroepen en de verschillende $t$-waarden per leeftijdsgroep. In fig. $1 \mathrm{~b}$ worden de data uit tab. 2 weergegeven.

\section{Discussie}

De uitkomsten van dit onderzoek tonen aan dat in het oudste cohort vrouwen de $\mathrm{W}_{\max } 10,1 \mathrm{~W} / \mathrm{m}^{2}$ lager is in vergelijking met het jongste cohort vrouwen. Bij mannen is het verschil tussen het oudste en het jongste cohort $7,5 \mathrm{~W} / \mathrm{m}^{2}$. Het gemiddelde verschil bij mannen is $0,08 \mathrm{~W} / \mathrm{m}^{2}$ per jaar en bij vrouwen $0,17 \mathrm{~W} / \mathrm{m}^{2}$. De verschillen in $W_{\max }$ tussen mannen en vrouwen zijn het meest evident in het leeftijdscohort $>50$ jaar (fig. 1b). Een $\mathrm{W}_{\max }$ van $10,6 \mathrm{~W} / \mathrm{m}^{2}$ wordt als normaal beschouwd $[9,10]$ en een negatief verschil van $1 \mathrm{~W} / \mathrm{m}^{2}$ kan grofweg vertaald worden naar circa $5 \%$ verlies van (maximale) contractiekracht. Een longitudinale interpretatie van deze cross-sectionele data suggereert dat 

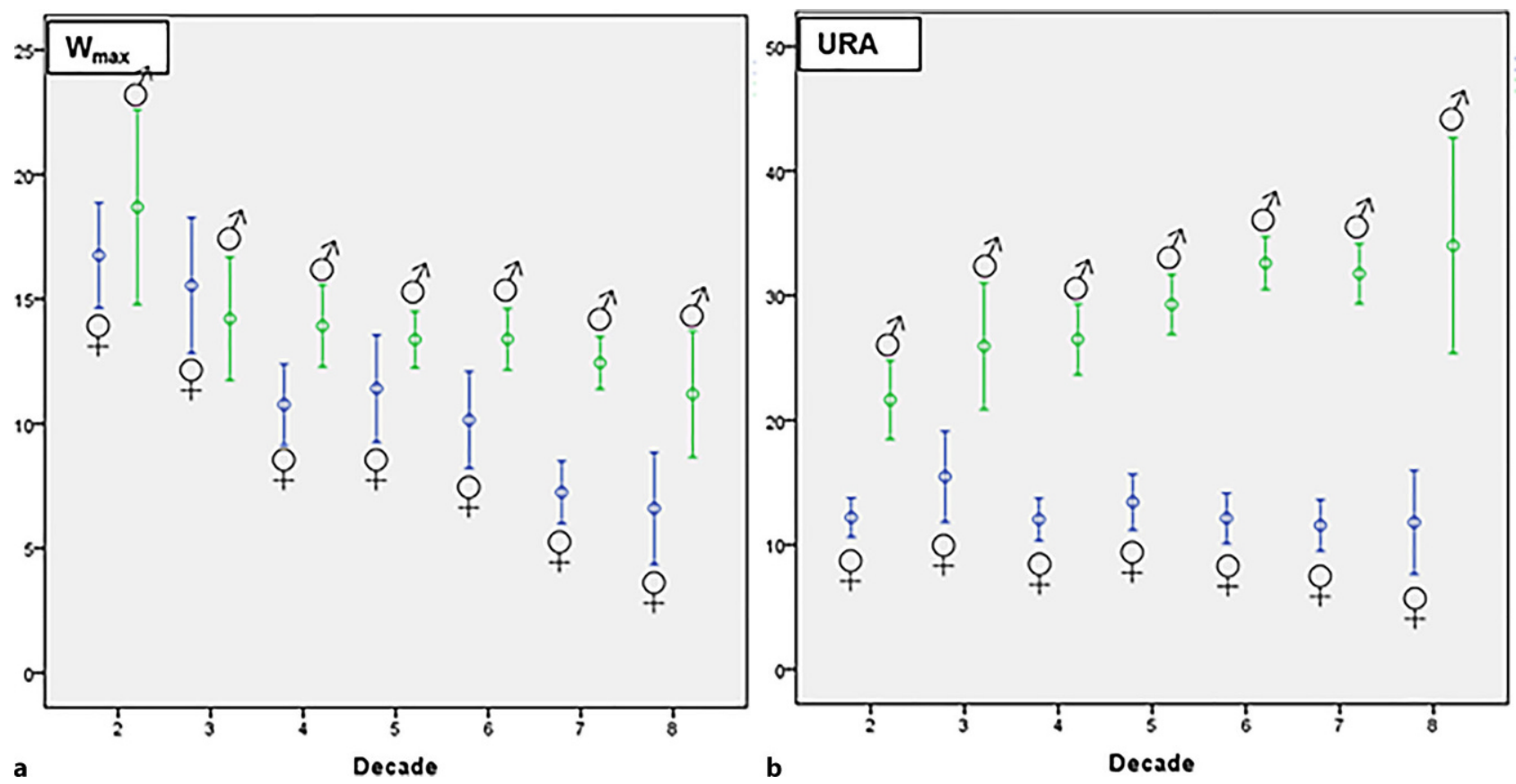

Figuur 1 a Scatterplot: $W_{\max }$ versus leeftijd. Mannen: Pearson $R^{2}=0,191$. Vrouwen: Pearson $R^{2}=-0,305$. b $W_{\max }$ en URA per leeftijdsdecade en geslacht: gemiddelde en standard error

mannen ongeveer $12 \%$ van hun maximale detrusorcontractie verliezen tussen hun $50^{\mathrm{e}}$ en $80^{\mathrm{e}}$ levensjaar, terwijl dat voor vrouwen circa $30 \%$ is.

De patiënten in dit onderzoek waren allen verwezen met LUTS. Daarnaast vallen patiënten die niet tot mictie konden komen, ofwel vanwege een werkelijke urineretentie of vanwege een situationeel onvermogen tot mictie, wel binnen het klinisch spectrum van DO, maar werden zij - logischerwijs - geëxcludeerd voor deze studie.

De mannelijke blaasuitgang, die een hogere uitgangsweerstand heeft, is geassocieerd met een enigszins sterkere contractie dan die van vrouwen. Dit is al het geval op een leeftijd van 20-50 jaar (tab. 2). In de groepen $>50$ jaar worden de geslachtsverschillen echter duidelijker (zie tab. 1 en 2 en fig. 1b). Mogelijk worden op deze leeftijd de klinische associatie tussen (voortdurende groei en) vergroting van de prostaat, en de daarmee stijgende prevalentie van blaasuitgangsobstructie met de leeftijd relevant [20]. In de eerste vier volwassen decaden is de $\mathrm{W}_{\max }$ bij mannen en vrouwen vergelijkbaar, vanaf het 50e leeftijdsjaar daalt de $\mathrm{W}_{\max }$ significant, voornamelijk bij vrouwen. Figuur $1 \mathrm{~b}$ suggereert, opnieuw in longitudinaal opzicht, dat de afname van de maximale contractiekracht voorkomen of vertraagd wordt door de uitdaging die de prostaat de detrusorspier biedt. Mogelijk heeft de langzaam groeiende prostaat tijdens elke mictie een trainingseffect op de detrusor, waardoor de spierkracht compensatoir toeneemt en/of hypertrofie ontstaat. Dit is aangetoond in pressure-flowstudies [7] en in proefdieronderzoek [18, 21, 22] en vervolgens bevestigd in klinische observaties [18]. In fig. $1 \mathrm{~b}$ is de relatie afgebeeld tussen de URA, de leeftijd en het geslacht. Dit maakt duidelijk dat de gemiddelde uitgangsweerstand niet significant verandert gedurende het leven van een vrouw, terwijl dit bij mannen wel een belangrijk fenomeen is.

Op basis van deze klinisch-epidemiologische waarnemingen kan verondersteld worden dat de vermoedelijke intrinsieke (met de leeftijd vorderende) afname van detrusorcontractiekracht, zoals gezien in dit cohort vrouwen, bij mannen vertraagd wordt ten gevolge van het door weerstand van de prostaat veroorzaakte trainingseffect.

Mogelijk hebben oestrogenen effect op de detrusorspier en mogelijk is de postmenopauze gerelateerd aan DO [19]. Testosteron heeft een mogelijk effect op glad spierweefsel [23]. Er is echter onvoldoende preklinisch bewijs om te concluderen dat de verschillen in contractiekracht tussen geslachten het directe gevolg zijn van verschillen in hormoonstatus.

Hoewel het kwantificeren van detrusorcontractiekracht met de in dit onderzoek gebruikte parameters algemeen geaccepteerd is, is geen van deze parameters een perfecte weergave van de werkelijke gladde spiercontractiliteit of -contractie [9]. Bij mannen met een relatief grote prostaat is er tijdens mictie een redelijk stabiele blaasuitgang, gelet op de balans tussen contractie en outflow. Bij vrouwen zijn de blaas en de uitgang van de blaas gedurende de mictie veel minder in balans. Bovendien is de uitgangsweerstand bij vrouwen door de kortere intra-abdominale urethra veel lager dan bij mannen, en mogelijk is daarom de invloed van het intra-abdominale gewicht en/of het 
Tabel 2 Mean $\mathrm{W}_{\max }$ per leeftijdsgroep

\begin{tabular}{|c|c|c|c|c|c|c|c|}
\hline \multirow{2}{*}{$\begin{array}{l}\text { leeftijdsdecade } \\
\text { leeftijd }\end{array}$} & \multicolumn{3}{|c|}{$\mathrm{W}_{\max }$ vrouwen } & \multicolumn{3}{|c|}{$\mathrm{W}_{\max }$ mannen } & \multirow{2}{*}{$\begin{array}{l}\mathrm{V}<>\mathrm{M} \\
\text { t test }\end{array}$} \\
\hline & $N$ & mean & sd & $N$ & mean & sd & \\
\hline $20-30$ & 72 & 16,7 & 8,9 & 45 & 18,7 & 13,1 & 0,386 \\
\hline $30-40$ & 37 & 15,5 & 8,3 & 44 & 14,2 & 8,2 & 0,470 \\
\hline $40-50$ & 55 & 10,7 & 6,0 & 109 & 13,9 & 8,6 & 0,016 \\
\hline $50-60$ & 82 & 11,4 & 9,7 & 210 & 13,4 & 8,2 & 0,082 \\
\hline $60-70$ & 73 & 10,1 & 8,3 & 227 & 13,4 & 9,3 & 0,008 \\
\hline $70-80$ & 45 & 7,2 & 4,2 & 125 & 12,4 & 5,9 & $<0,001$ \\
\hline $80-90$ & 5 & 6,6 & 2,5 & 28 & 11,2 & 6,7 & $N$ te klein \\
\hline ANOVA & & $<0,001$ & & & 0,002 & & \\
\hline gemiddelde allen & 369 & 11,9 & 8,6 & 788 & 13,6 & 8,7 & 0,003 \\
\hline
\end{tabular}

gebruik van buikspieren op de flow voor vrouwen groter dan bij mannen [10].

In deze studie worden alleen de resultaten van normale micties gepresenteerd; opvallend persen is daarmee geëxcludeerd. Bovendien zijn voor de analyse piekartefacten van de $p_{\text {det }} Q_{\max }$ gecorrigeerd. De data tonen echter dat er uitschieters bij zaten, met name in $\mathrm{W}_{\max }$. Een specifieke leeftijdgerelateerde confounder, door persen of andere piekartefacten, is onwaarschijnlijk. Uitschieters in $\mathrm{W}_{\max }$ hadden geen relatie met leeftijd of geslacht (fig. 1). $\mathrm{W}_{\max }$ is voorafgaand aan de $\mathrm{p}_{\text {det }} \mathrm{W}_{\max }$ normaal verdeeld.

Hoewel aangenomen wordt dat de $\mathrm{W}_{\max }$ een nauwkeurige bepaling is, zijn de resultaten vergelijkbaar met die van de BCI (correlaties in tab. 1; [8]). Op dit moment is het onduidelijk of een van de parameters om detrusorcontractiekracht te kwantificeren betrouwbaarder is dan de andere, vooral omdat er slechts schaarse informatie beschikbaar is over de klinische reproduceerbaarheid van deze parameters. Het grote aantal metingen dat in ons onderzoek is geanalyseerd (uitgezonderd de 80-plussers) geeft ons onderzoek voldoende statistische power voor epidemiologische analyse en voorkomt dat uitschieters te veel invloed hebben.

Dat in onze cross-sectionele studie de maximale detrusorcontractiekracht met name bij vrouwen afneemt met de leeftijd, bevestigt mogelijk opnieuw dat de functie van glad spierweefsel in de loop der jaren afneemt. Idealiter wordt deze waarneming in een longitudinale follow-up studie bevestigd, ongeacht de aanwezigheid van klachten en ongeacht of het een gezonde proefpersoon of een patiënt betreft. De realiteit is dat dergelijke studies met invasieve onderzoeken ethisch lastig op te zetten zijn.

\section{Conclusie}

De relatie tussen maximale detrusorcontractiekracht tijdens een subjectief representatieve mictie van (klinisch) verwezen patiënten met LUTS werd in een cross-sectionele studie geanalyseerd in relatie tot leeftijd en geslacht. We constateerden een lagere maximale detrusorcontractiekracht in hogere leeftijdsgroepen, zowel bij mannen als bij vrouwen. Bij oudere vrouwen toonde de maximale detrusorcontractiekracht, in relatie met vorderende leeftijd, meer afname dan bij mannen in een vergelijkbare leeftijdsrange. Deze data kunnen niet zonder meer gegeneraliseerd worden naar een asymptomatische populatie.

Open Access This article is distributed under the terms of the Creative Commons Attribution 4.0 International License (http://creativecommons.org/licenses/by/4.0/), which permits unrestricted use, distribution, and reproduction in any medium, provided you give appropriate credit to the original author(s) and the source, provide a link to the Creative Commons license, and indicate if changes were made.

\section{Literatuur}

1. Aunan JR, Watson MM, Hagland HR, Sùreide K. Molecular and biological hallmarks of ageing. Br J Surg. 2016;103:e29-e46.

2. Osman NI, Chapple CR. Contemporary concepts in the aetiopathogenesis of detrusor underactivity. Nat Rev Urol. 2014;11:639-48.

3. Vahabi B, Wagg AS, Rosier PFWM, et al. Can we define and characterize the aging lower urinary tract?-ICI-RS2015. Neurourol Urodyn. 2017;36:854-8.

4. Abrams P, Cardozo L, Fall M, et al. The standardisation of terminology in lower urinary tract function: report from the standardisation sub-committee of the International Continence Society. Urology. 2003;61:37-49.

5. Chapple CR, Osman NI, Birder L, et al. The underactive bladder: a new clinical concept? Eur Urol. 2015;68:351-3.

6. Schaefer W. Analysis of bladder-outlet function with the linearized passive urethral resistance relation, linPURR, and a disease-specific approach for grading obstruction: from complex to simple. World J Urol. 1995;13:47-58.

7. Rosier PF, de Wildt MJ, de la Rosette JJ, Debruyne FM, Wijkstra H. Analysis of maximum detrusor contraction power in relation to bladder emptying in patients with lower urinary tract symptoms and benign prostatic enlargement. J Urol. 1995;154:2137-42.

8. Donkelaar SCT, Rosier P, Kort L de. Comparison of three methods to analyse detrusor contraction during micturition in men over 50 years of age. Neurourol Urodyn. 2017;36(8):2153-9.

9. GriffithsD.Detrusor contractility-orderout of chaos. Scand JUrol Nephrol Suppl. 2004;93:100.

10. Griffiths DJ. The mechanics of the urethra and of micturition. BrJ Urol. 1973;45:497-507.

11. DewulfK, Abraham N, LambLE, etal. Addressing challenges in underactive bladder: recommendations and insights 
from the Congress on Underactive Bladder (CURE-UAB). Int Urol Nephrol. 2017;49:777-85.

12. Budui SL, Rossi AP, Zamboni M. The pathogenetic bases of sarcopenia. Clin Cases Miner Bone Metab. 2015;12:22-6.

13. Bitar KN, Patil SB. Aging and gastrointestinal smooth muscle. Mech Ageing Dev. 2004;125:907-10.

14. Owens GK, Kumar MS, WamhoffBR. Molecular regulation of vascularsmoothmuscle cell differentiationin development and disease. Physiol Rev. 2004;84:767-801.

15. Gibson W, Wagg A. Incontinence in the elderly, 'normal' ageing, or unaddressed pathology? Nat Rev Urol. 2017;14:440-8.

16. Jeong SJ, Kim HJ, Lee YJ, et al. Prevalence and clinical features of detrusor underactivity among elderly with lower urinary tract symptoms: a comparison between men and women. Korean J Urol. 2012;53:342-8.

17. Pfisterer MH, Griffiths DJ, Schaefer W, Resnick NM. The effect of age on lower urinary tract function: a study in women. JAm Geriatr Soc. 2006;54:405-12.

18. Lecamwasam HS, Yalla SV, Cravalho EG, Sullivan MP. The maximum watts factor as a measure of detrusor contractility independent of outlet resistance. Neurourol Urodyn. 1998;17:621-35.
19. Taylor JA 3rd, Kuchel GA. Detrusor underactivity: Clinical features and pathogenesis of an underdiagnosed geriatric condition. JAm Geriatr Soc. 2006;54:1920-32.

20. Bosch JL, Bangma CH, Groeneveld FP, Bohnen AM. The longterm relationship between a real change in prostate volume and a significant change in lower urinary tract symptom severity in population-based men: the Krimpen study. Eur Urol. 2008;53:819-25; discussion 825-7.

21. Damaser MS, Haugaard N, Uvelius B. Partial obstruction of the rat urinary bladder: effects on mitochondria and mitochondrial glucose metabolism in detrusor smooth muscle cells. Neurourol Urodyn. 1997;16:601-7.

22. Gosling JA, Kung LS, Dixon JS, et al. Correlation between the structure and function of the rabbit urinary bladder following partial outlet obstruction. J Urol. 2000;163:1349-56.

23. Gonzalez-Montelongo MC, Marín R, Gomez T, Díaz M. Androgens are powerful non-genomic inducers of calcium sensitization in visceral smooth muscle. Steroids. 2010;75:533-8.

Peter F.W.M. Rosier, artsfunctionele urologie

Celine S. ten Donkelaar, uroloog in opleiding

prof. dr. Laetitia M.O. de Kort, uroloog 